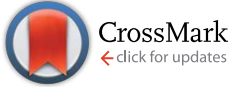

Cite this: RSC Adv., 2017, 7, 12897

Received 28th November 2016 Accepted 19th February 2017

DOI: $10.1039 / c 6 r a 27454 d$

rsc.li/rsc-advances

\section{Sterical ligand stabilization of nanocrystals versus electrostatic shielding by ionic compounds: a principle model study with TEM and XPS $\uparrow$}

\begin{abstract}
Lars Mohrhusen* and Milena Osmić
Colloidal metal nanoparticles are usually fabricated via the reduction of metal salt precursor compounds in liquid phase. To prevent agglomeration, organic capping agents are used. Commonly, it is neglected that ionic compounds may coadsorb when present in the mixture. However, we shall show that ionic adsorbates play a key role in size and growth control. We present a universal case study on gold nanoparticles with various amine ligands to reveal two competitive stabilization mechanisms via quantitative $X$-ray photoelectron spectroscopy (XPS) and transmission electron microscopy (TEM). Gold nanocrystals were obtained starting with a single phase room temperature synthesis. The stabilization turned out to be a combination of sterical and electrostatic shielding depending on the ligand molecule properties. We can adjust the ratio of both contributions via simple liquid phase ligand exchange procedures at moderate temperatures as shown with XPS. Apparently, ions further have the power to steer different ripening processes. HR-TEM studies proved that there is no influence on nanoparticle morphology during heat treatment or ligand exchange. Introducing a lack of stabilization by weaker sterical ligands offers an auspicious new way for the synthesis of porous nanomaterials. The novel findings illustrate that electrostatic stabilization by coadsorbed ionic compounds can play a crucial role in understanding various experimental results and thus the colloidal synthesis of nanomaterials in general appears in a new light.
\end{abstract}

\section{Introduction}

Nanostructured materials of different compositions have attracted attention in several fields of science and technology. ${ }^{1-5}$ Especially, noble metal nanoparticles are designed and studied for many applications in a wide variety of disciplines. Drug delivery, ${ }^{6,7}$ biological imaging, and theranostics, ${ }^{3,8,9}$ molecular sensing, ${ }^{\mathbf{1 0 , 1 1}}$ photovoltaics, ${ }^{12}$ or printable nanostructures for microelectronics ${ }^{\mathbf{1 3}}$ are only a few examples. ${ }^{\mathbf{1 4 , 1 5}}$ Another important application is heterogeneous catalysis concerning more than $90 \%$ of production processes in industrial chemistry. ${ }^{\mathbf{1 6 , 1 7}}$ Catalytic applications are used as an example to stress the importance of well-defined gold nanoparticles for science and technology.

As bulk gold exhibits no special catalytic activity, first results in the 1980 s by Haruta et al. on the catalytic activity of gold nanoparticles in low-temperature CO oxidation and by Hutchings et al. in hydrochlorination of ethine were groundbreaking for the catalytic use of nanoscaled gold particles on different supporting materials as heterogeneous catalysts. ${ }^{18-24}$ Nowadays, gold nanocatalysis is of importance for various reactions like

Carl von Ossietzky University of Oldenburg, Institute of Chemistry, Physical Chemistry 1, D-26129 Oldenburg, Germany. E-mail: lars.mohrhusen@uni-oldenburg.de

$\dagger$ Electronic supplementary information (ESI) available: Statistical size analysis of TEM micrographs, scheme illustrating the size change during purification, XPS survey and Au4f detail spectra. See DOI: 10.1039/c6ra27454d hydrogenations ${ }^{\mathbf{1 8 , 2 5}}$ or selective and partial oxidations $\mathbf{s}^{\mathbf{2 6 - 2 8}}$ for the production of many basic chemical compounds. Furthermore, gold catalysts are also used for some special reactions, for example, the $\mathrm{NO}_{x}$ reduction. ${ }^{29-31}$ Interactions with support materials such as various transition metal oxides are of significant importance. ${ }^{32-38}$

As the catalytic properties of nanomaterials crucially depend on size,$^{\mathbf{3 9 , 4 0}}$ shape, ${ }^{\mathbf{4 0 , 4 1}}$ and perimeter sites at support materials ${ }^{\mathbf{1 9 , 4 0 , 4 2 - 4 8}}$ it is important to provide uniform nanoparticles with distinct surfaces. Colloidal chemistry allows preparation of such nanocrystals with well-defined composition, size, and shape of various materials. ${ }^{\mathbf{4 9}-52}$ As the catalytic properties like activity and selectivity can be influenced by the stabilizing ligands, colloidal nanoparticles are recently tested for such applications. ${ }^{53-56}$ Effects on the strong metal support interaction (SMSI) encountered in conventional metal oxide support systems are of vital interest. ${ }^{57,58}$ Weakly bound amine ligands appear to be promising candidates for such applications. ${ }^{\mathbf{2 6 , 5 9 , 6 0}}$

Coming from early synthetic routes ${ }^{61-63}$ several new methods were developed over the last decades to provide custom-made and well-defined colloidal gold nanoparticles for many requirements. Today there is a huge number of recipes available for the synthesis of gold particles with various shapes and sizes in organic or aqueous phases as well as in binary systems..$^{3,4,49,50,64-67}$ In order to prevent agglomeration, numerous molecular compounds like organic thiols, ${ }^{12,68,69}$ amines $^{70-72}$ and 
phosphines $^{73-75}$ have been tested for nanoparticle stabilization. Also, various polymers ${ }^{76-78}$ as well as different ionic compounds like citrate,$^{79,80}$ quaternary ammonia compounds ${ }^{81,82}$ or ionic liquids ${ }^{83-85}$ have been studied for their ligand properties. Many synthesis methods are limited in terms of sustainability because special reaction conditions like elevated temperatures, ${ }^{\mathbf{8 6}}$ additional chemicals such as phase transfer catalysts ${ }^{64,87}$ or ripening agents $^{\mathbf{8 8 , 8 9}}$ are required. Furthermore, a couple of treatments for purification $^{90,91}$ and functionalization ${ }^{12,92,93}$ are available according to the literature. The high number of corresponding publications illustrates the promising potential for gold nanomaterials but also indicates that a closer look at the surface of the nanoparticles is mandatory to understand their properties and characteristics. ${ }^{4}$

The earlier synthesis of small gold nanoparticles with amine ligands was made using a single phase method in organic solution by Jana and Peng using gold trichloride as a source for gold monomers, a borohydride compound as reducing agent and quaternary ammonia compounds for solubility mediation. ${ }^{94}$ However, Jana and Peng did not investigate the exact surface composition, which is, as will be shown here, probably a major set screw for nanoparticle synthesis in general. For a universal model study, this method was adopted and modified with respect to higher amounts of ligands, different amine molecules, solvents and lower temperature for heat treatment and ligand exchange procedures. This is a straightforward and easy to modify method at ambient conditions and without using high, energy-intensive temperatures above $325 \mathrm{~K}$.

In the following, we will demonstrate that ionic compounds play a major role in stabilizing gold nanoparticles with various amine ligands. Furthermore, new heat treatment and ligand exchange procedures at lower temperatures will be discussed from transmission electron microscopy (TEM) studies. Quantitative X-ray photoelectron spectroscopy (XPS) results will provide a novel closer look towards the nanoparticle surface stabilization. The literature synthesis is suitable for the fabrication of many (noble) metal nanoparticles ( $\mathrm{Au}, \mathrm{Ag}, \mathrm{Cu}, \mathrm{Pt} . .$. with different kinds of ligands like thiols, ammonia compounds or carboxylic acids.

\section{Materials}

Gold trichloride $\left(\mathrm{AuCl}_{3}, 99.99 \%\right)$ was purchased from Acros Organics. Didodecyldimethylammonium bromide (DDAB, 98\%), tetrabutylammonium borohydride (TBAB, 98\%), dodecylamine (DDA, 98\%), oleylamine (OA, 70\%) and trihexylamine (THA, 96\%) were provided by Sigma Aldrich. Toluene (99.95\%), hexane $(95.7 \%)$ and isopropanol $(99.7 \%)$ were bought from VWR. Acetone (99\%) and methanol (99.99\%) were purchased from Fisher Scientific. All chemicals were used without further purification. Except for the solvents, all chemicals were stored in a refrigerator at $280 \mathrm{~K}$.

\section{Procedures}

\section{Basic synthesis of gold nanoparticles with amine ligands}

$7.5 \mathrm{mg}(0.025 \mathrm{mmol})$ of $\mathrm{AuCl}_{3}$ and $186.0 \mathrm{mg}$ (1.000 mmol) DDA (3.33 $\mathrm{ml}$ OA or $3.39 \mathrm{ml}$ THA respectively) was dissolved in $2.5 \mathrm{ml}$ toluene. For a second solution $25.0 \mathrm{mg}(0.097 \mathrm{mmol})$ of TBAB and $46.3 \mathrm{mg}(0.100 \mathrm{mmol}) \mathrm{DDAB}$ was dissolved in $1.0 \mathrm{ml}$ toluene. After a few minutes of sonication, both solutions appear free of any unsolved solids. In the following, the second solution was abruptly injected into the first solution stirred by a magnetic bar at a constant temperature of $290 \mathrm{~K}$. Immediate color change from yellowish orange to deep red indicated the beginning of the formation of nanoparticles. Slow hydrogen evolution was observed. After stirring for 60 minutes at $290 \mathrm{~K}$, $100 \mu \mathrm{l}$ of the particle solution was transferred to a small centrifugation container (PP). For purification $900 \mu \mathrm{l}$ acetone was added. Centrifugation for 10 minutes at $11500 \mathrm{rpm}$ lead to precipitation of the particles at the bottom of the container. The sediment could be easily dissolved in $1.0 \mathrm{ml}$ hexane.

Higher amounts for further treatments like the ligand exchange procedure were purificated by adding the fourfold amount of acetone followed by centrifugation at $3500 \mathrm{rpm}$. The precipitate was also dissolved in hexane.

\section{Heat treatment procedure}

Furthermore, a heat treatment procedure was developed to investigate the influence of temperature. For this purpose, the reaction mixture before purification was equipped with a reflux cooling unit and stirred for 60 minutes at a temperature of 325 $\mathrm{K}$. Then the purification process was performed as described above.

\section{Ligand exchange procedure}

After purification of the reaction solution, the precipitate was dissolved in $3.0 \mathrm{ml}$ of toluene instead of hexane. Then $1.0 \mathrm{mmol}$ of the corresponding ligand was added. The mixture was heated to $325 \mathrm{~K}$ equipped with a reflux cooling unit and stirred for 60 minutes while keeping the temperature. Afterward, a second purification step was performed following the same procedure.

\section{Characterization}

Samples for TEM analysis were prepared by dropping $7.5 \mu \mathrm{l}$ of the diluted solution onto a carbon-coated copper grid and subsequent drying in air at room temperature. TEM studies were performed with a Zeiss EM 902A operating at $80 \mathrm{kV}$ while high resolution (HR-)TEM, scanning (S-)TEM and energy dispersive X-ray spectroscopy (EDX) measurements were obtained with a JEOL $2100 \mathrm{~F}$ electron microscope operating at 200 $\mathrm{kV}$.

TEM micrographs were statistically analyzed to evaluate the size and size distribution of the nanoparticles. For this purpose, more than 1000 particles in every sample were measured in minor and major diameter to get a mean diameter using ImageJ 1.49 for analysis.

For XPS analysis the solution was dropped onto a silicon wafer and dried in air at room temperature. Silicon wafers were cleaned by sonication in acetone and isopropanol for five minutes each before use. XPS investigations were made with a Thermo Fisher ESCALAB 250Xi machine using charge compensation and monochromatic $\mathrm{Al} \mathrm{K} \alpha$ radiation. All XPS spectra were calibrated to the C1s signal at $284.6 \mathrm{eV}$ binding 
energy ${ }^{95}$ All detailed spectra were measured with an energy step size of $0.05 \mathrm{eV}$ with $100 \mathrm{~ms}$ dwell time, pass energy of $10 \mathrm{eV}$ and averaged over 10 scans. For quantification N1s, Br3d and Cl2p signals were additionally measured with $100 \mathrm{eV}$ pass energy for higher sensitivity apart from the same other conditions. Quantification of the XPS results was done using fits with Casa XPS 2.3.15.

\section{Results and discussion}

In the present work, new insights in the stabilization of small gold nanoparticles with different amine ligands will be presented. Therefore, the surprising role of ionic compounds in stabilization and heat treatment procedures will be demonstrated from TEM studies as well as quantitative XPS results.

The heat treatment can induce different growth effects depending on the used ligand. One should note that two different transformation processes may occur: Ostwald ripening leading to an increase in size and digestive ripening associated with a decrease in particle size. Both are observed and wellknown processes as discussed in the literature. ${ }^{88,96,97}$

The ligand exchange in case of gold oleylamine (Au OA), gold dodecylamine (Au DDA), and gold trihexylamine (Au THA) nanoparticles is not a standard exchange procedure as it represents a method to decrease ionic contaminations via replacement by amine molecules as will be shown later. This procedure allows to increase the amount of amine on the particle surface and to decrease the amount of contaminations originating from the reaction mixture. In contrast, in literature the possibility for coadsorbates is often neglected by assuming a complete exchange of the used ligands. ${ }^{12,92,98}$ This recipe is suitable for many amine ligands as long as the amine can provide enough sterical stabilization to prevent agglomeration.

\section{A new synthetic route towards small gold nanoparticles - TEM studies}

To examine the impact of different stabilizing agents, three amines were chosen as model ligands. OA is a ligand with a long hydrocarbon chain in comparison to DDA with a shorter chain. Furthermore, THA was chosen as an example for a ligand with a short hydrocarbon chain and a high sterical demand in the lateral direction. To investigate the role of ammonia compounds gold didodecyldimethylammonium bromide (Au DDAB) nanoparticles were generated by using the same amount of DDAB instead of an amine. One should keep in mind that

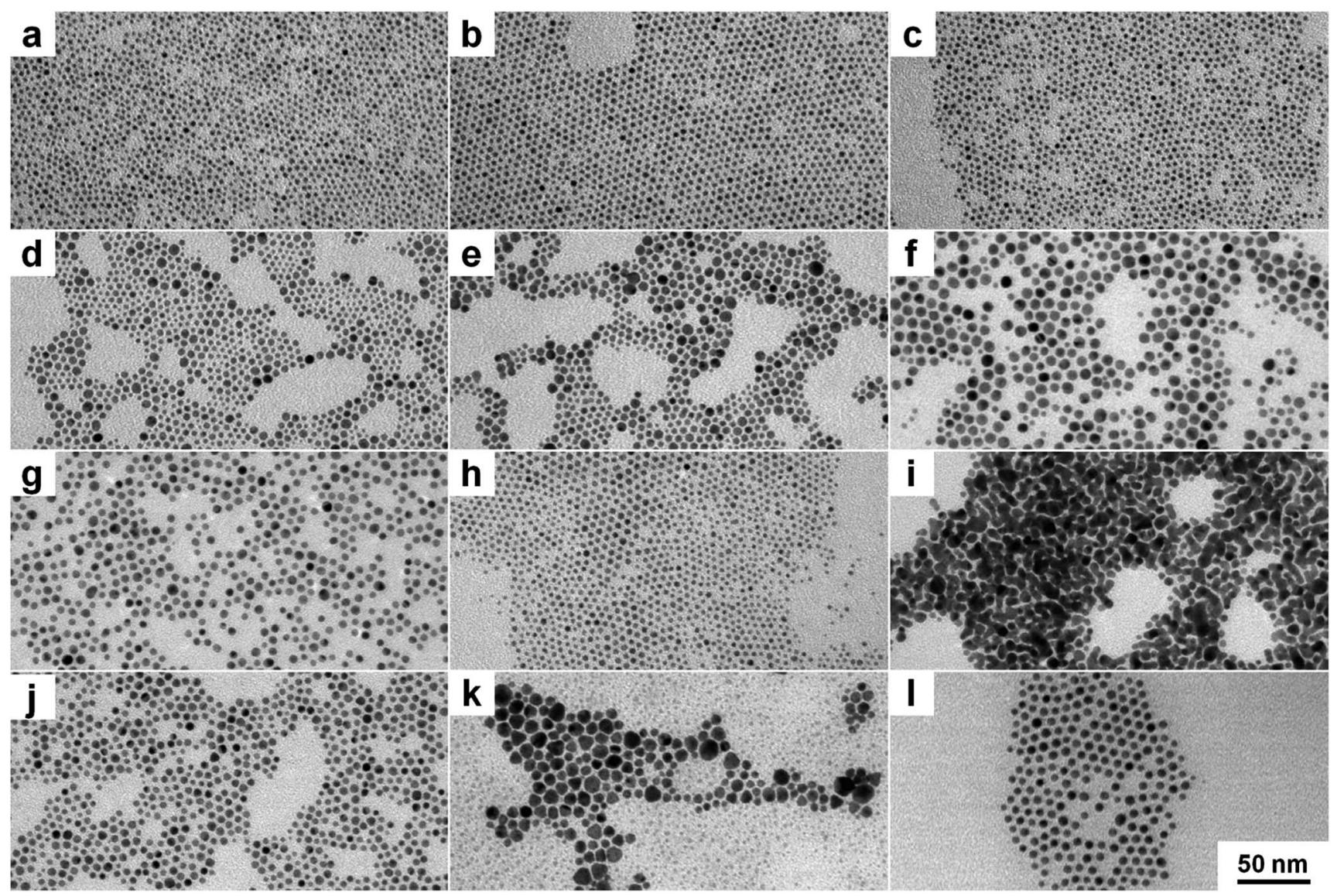

Fig. 1 TEM-studies of Au nanocrystals with different ligands. The left column ( $a, d, g$ and $j$ ) shows nanoparticles as synthesized, the middle column ( $b, e, h$ and $k$ ) after heat treatment and the right column ( $c, f, i$ and $l$ ) after ligand exchange. (l) shows Au DDAB nanoparticles after ligand exchange with OA. The first row shows Au OA $(a-c)$, the second Au DDA (d-f), the third Au THA ( $g-i)$ and the fourth Au DDAB (j-l) nanoparticles, respectively. All TEM micrographs are showing nanoparticles after purification with magnification $140 \mathrm{k}$ obtained at $80 \mathrm{kV}$. 
DDAB has not only sterical but also electrostatic forces to prevent agglomeration and growth. Fig. 1 shows representative TEM micrographs of different nanocrystals. Fig. 1a, d, g and j show as-synthesized nanoparticles after purification. Fig. 1b, $\mathrm{e}, \mathrm{h}$, and $\mathrm{k}$ present nanoparticles after heat treatment and purification. Finally, Fig. 1c, f, i and 1 show nanoparticles after heat treatment, purification, ligand exchange, and second purification. Most of the nanoparticles are roughly spherical. In a few cases, tetrahedral or octahedral structures (not shown) can be found randomly without correlation to experimental parameters. Results of the statistical size analysis are summarized in Table 1. Corresponding histograms for size distribution are available in the ESI. $\dagger$

Au OA nanoparticles (Fig. 1a-c) are relatively small exhibiting a quite narrow size distribution due to the high sterical stabilization by the long hydrocarbon chain. They are not prone to changes in size or size distribution during heat treatment or ligand exchange procedures. This suggests a strong stabilization by the sterical forces of the OA molecules.

DDA has a smaller hydrocarbon chain length in comparison to OA. It appears to be a weaker stabilizing agent as apparent from the occurrence of bigger particles as displayed in Fig. 1d-f. $\mathrm{Au}$ DDA nanoparticles increase in size during heat treatment and ligand exchange because the stabilizing effect of DDA is apparently not strong enough to prevent growth consuming monomers originating from smaller particles.

Fig. 1g-i show Au THA nanocrystals. At first, Au nanoparticles with tertiary amines like THA lead to similar particles like Au DDA. However, heat treatment produces smaller particles. Ligand exchange with THA results in aggregation of the nanoparticles to "nanoporous"-like structures. Tertiary amines have a high sterical demand also in the lateral direction so that the surface density of the ligand is supposed to be lower compared to primary amines. In the case of THA, the sterical forces of the relatively small hydrocarbon chains are weak and apparently do not play a superior role in stabilizing the nanoparticles. This indicates different initial stabilization mechanisms in comparison to Au DDA and THA.

As the hydrocarbon chain length is comparable, Au DDAB nanoparticles are similar to Au DDA NPs in size and size distribution. In contrast to Au THA nanocrystals, heat treatment starts Ostwald ripening in the case of Au DDAB nanoparticles. The breakup of smaller particles results in the growth of bigger ones. The appearance of smaller and bigger particles in Fig. 1k illustrates this effect. Ligand exchange with $\mathrm{OA}$ as a strong ligand produces uniform particles again (Fig. 11).

This basic synthesis method is a simple one-phase approach in organic solution. Due to the high number of parameters like concentration, humidity, stirring, contaminations and inhomogeneities, the reproduction is restricted. Temperature is a major set screw with high impact on many aspects of nanoparticle formation. Even a slight temperature change of a few Kelvin can induce dramatic effects for size and shape control. Therefore, water bath cooling to constant $290 \mathrm{~K}$ for synthesis and heating with an oil bath to constant $325 \mathrm{~K}$ for heat treatment and ligand exchange is mandatory to get reproducible results.

Another important impact factor is the purification procedure as it induces dramatic changes in size and size distribution of the nanoparticles. TEM measurements of uncleaned samples reveal much smaller particles than those resulting from the precipitate (see ESI, Fig. S2 $\dagger$ ), which could be due to partial removal of excessive ligands and is somewhat sensitive to the used precipitation agent.

This is a problem considering that very defined and clean nanoparticles are desired for many applications which is

Table 1 Statistic size evaluation of Au nanoparticles with different ligands after purification with acetone. The mean diameter and the standard deviation were obtained from TEM micrographs (magnification 140k) using ImageJ 1.49

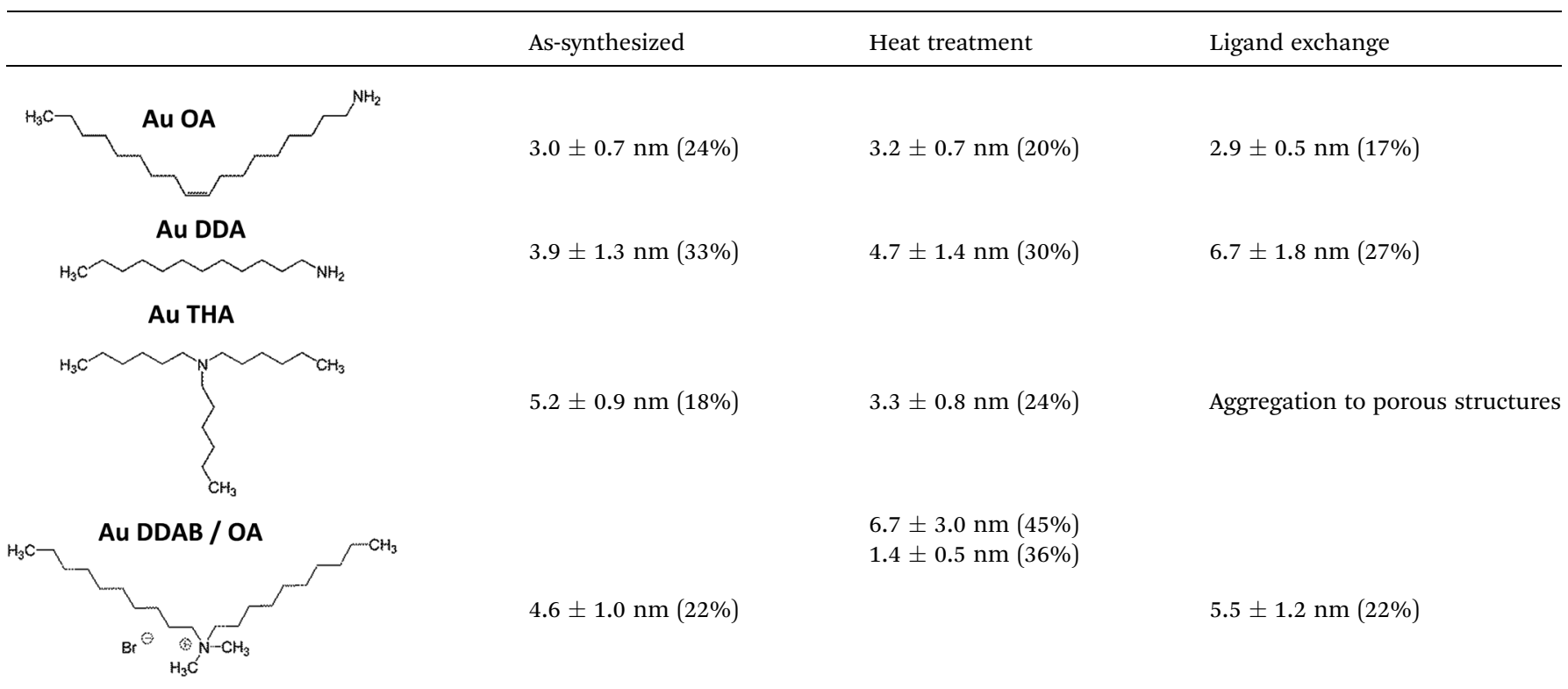


addressed by employing several precipitation and centrifugation steps. ${ }^{\mathbf{1 4 5 4 , 9 9}}$ In our case, multiple purification steps are not a suitable answer as it leads to further agglomeration with each step. However, the impact of the precipitation agent is restricted, as it needs to be polar enough to induce a precipitation of sufficient amounts of nanoparticles. On the other hand, too high polarity leads to agglomeration when removing too many surfactants. For example, several alcohols like methanol show similar results as acetone for Au OA, Au DDA, and Au THA nanoparticles. In contrast, purification with methanol leads to complete agglomeration in the case of the Au DDAB nanocrystals. This indicates the total removal of DDAB via methanol precipitation and a different stabilizing mechanism in case of Au DDAB nanoparticles.

To obtain information on the microstructure of the nanoparticles HR-TEM studies were done. Au DDA nanoparticles were used as a representative example. Investigations on Au OA, $\mathrm{Au}$ THA, and Au DDAB nanostructures generated similar results.

All investigated nanostructures are highly crystalline. Even for smaller particles, no amorphous structures were found. In all cases, single-crystalline particles, as well as defective ones with several phase boundaries and twin defects, could be found.

Fig. 2 shows exemplified TEM micrographs for singlecrystalline (a and d) and polycrystalline or defective (e and h) nanocrystals. Fig. 2a and e represent the as-synthesized material after purification. Fig. $2 \mathrm{~d}$ and h show the nanocrystals after heat treatment, purification, ligand exchange, and second purification.

The lattice distance for most of the particles (>90\%) is 236.7 $\pm 1.9 \mathrm{pm}$. This indicates a face-centered cubic (111) surface and is in good agreement with the literature. ${ }^{\mathbf{1 0 0}}$ HR-TEM micrographs and corresponding fast Fourier transformation (FFT) pictures of single particles support this observation. Only a few $(<10 \%)$ other crystal planes, mainly face-centered cubic (200)

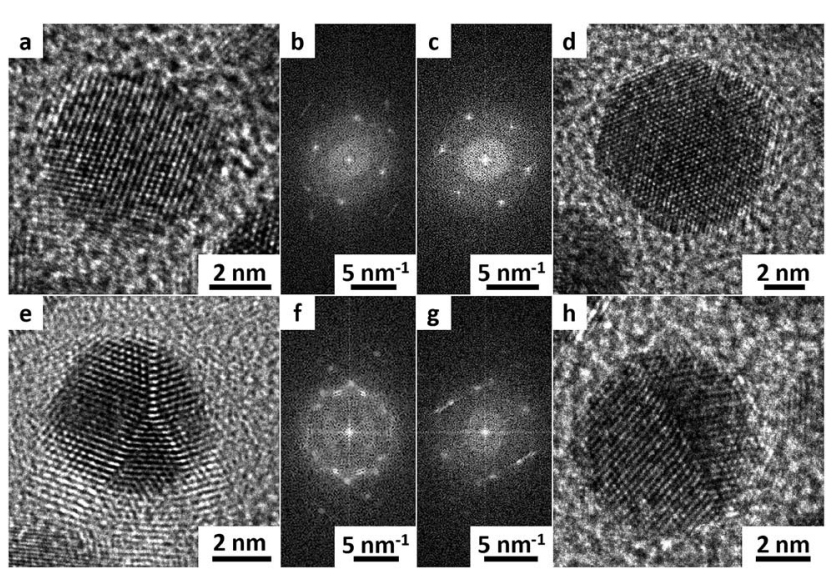

Fig. 2 Representative HR-TEM micrographs of single Au DDA nanocrystals ( $a, d, e$ and $h$ ) and corresponding FFTs (b, c, f, and g) obtained with $200 \mathrm{kV}$. Left ( $a, b$, e and f): as synthesized after purification. Right (c, $\mathrm{d}, \mathrm{g}$ and $\mathrm{h}$ ): after heat treatment, ligand exchange and second purification. In both cases frequently single-crystalline structures were found as well as defective polycrystalline particles. could be found as evidenced from lattice distance, atomic resolution TEM micrographs, and FFTs.

Surprisingly, neither heat treatment nor ligand exchange procedure have a measurable influence on the crystallinity of the nanoparticles. This illustrates that the crystal structure has no obvious impact on the possible agglomeration of these gold nanoparticles.

\section{Determining the surfactant composition - XPS investigations}

TEM investigations indicated that the situation at the surface of the nanoparticles is dependent on the characteristic properties of the ligand molecules as well as other adsorbed surfactants.

XPS is a useful tool to determine the composition of the nanoparticles as it is especially sensitive to the surface structure and has the ability to detect and quantify different chemical species.

Survey XPS spectra of the gold nanoparticles deposited on a silicon wafer with a native oxide surface are showing typical signals corresponding to carbon, oxygen, gold, nitrogen, chlorine, bromine and silicon from the sample support (see Fig. S3 in ESI $\dagger$ ). Detailed spectra of the C1s, O1s, Au4f, N1s, Cl2p, Br3d and Si2p regions were measured to identify the different chemical species. All XPS signal positions are given in binding energies.

XPS results prove that all nanoparticles consist of gold in oxidation state 0 with two spin-orbit split signals for the Au4f $\left(\mathrm{Au} 4 \mathrm{f}_{7 / 2}\right.$ around $83.7 \mathrm{eV}, \mathrm{Au}_{4} \mathrm{f}_{5 / 2}$ around $87.2 \mathrm{eV}$, respectively). This is in good agreement with the literature. ${ }^{66,101-103}$ One should note that our signals are slightly shifted (not more than $0.4 \mathrm{eV}$ ) depending on the surfactant composition. A detailed representative spectrum of the Au4f region obtained from $\mathrm{Au}$ DDA nanoparticles is provided in Fig. S4 in the ESI. $\dagger$

Detailed spectra of Au DDA nanoparticles for the N1s, Br3d, and $\mathrm{Cl} 2 \mathrm{p}$ region are shown in Fig. 3. Again, Au DDA nanoparticles serve as a representative example, as Au THA, Au OA, and $\mathrm{Au} \mathrm{DDAB}$ nanoparticles gave similar results. The left column shows results from the as-synthesized material after purification. The right column presents data from the same material after heat treatment, purification, ligand exchange, and second purification. First, the as-synthesized material will be discussed.

Two different species containing nitrogen are easily distinguished as there is no spin-orbit splitting in a 1s signal. One species at $398.9 \mathrm{eV}$ can be attributed to the amine ligand. The second species can be related to a quaternary ammonia compound resulting in the signal at $401.4 \mathrm{eV}$. Reference measurements on pure compounds interaction with the silicon support proved that the first signal belongs to the amine ligand (398.9 eV) while the second signal corresponds to ammonia nitrogen (401.4 eV). This is in good agreement with the literature. ${ }^{104}$ With respect to the high sterical demand of the tetrabutylammonium ion (from TBAB), one can assume that the coadsorbed ammonia compound is didodecyldimethylammonium from DDAB. The ratio of those two signal intensities is dependent on the ligand as will be pointed out later.

The spectra for the Br3d region exhibit two signals from spin-orbit-splitting corresponding to the $\mathrm{Br}_{3 / 2}$ at $66.9 \mathrm{eV}$ and 

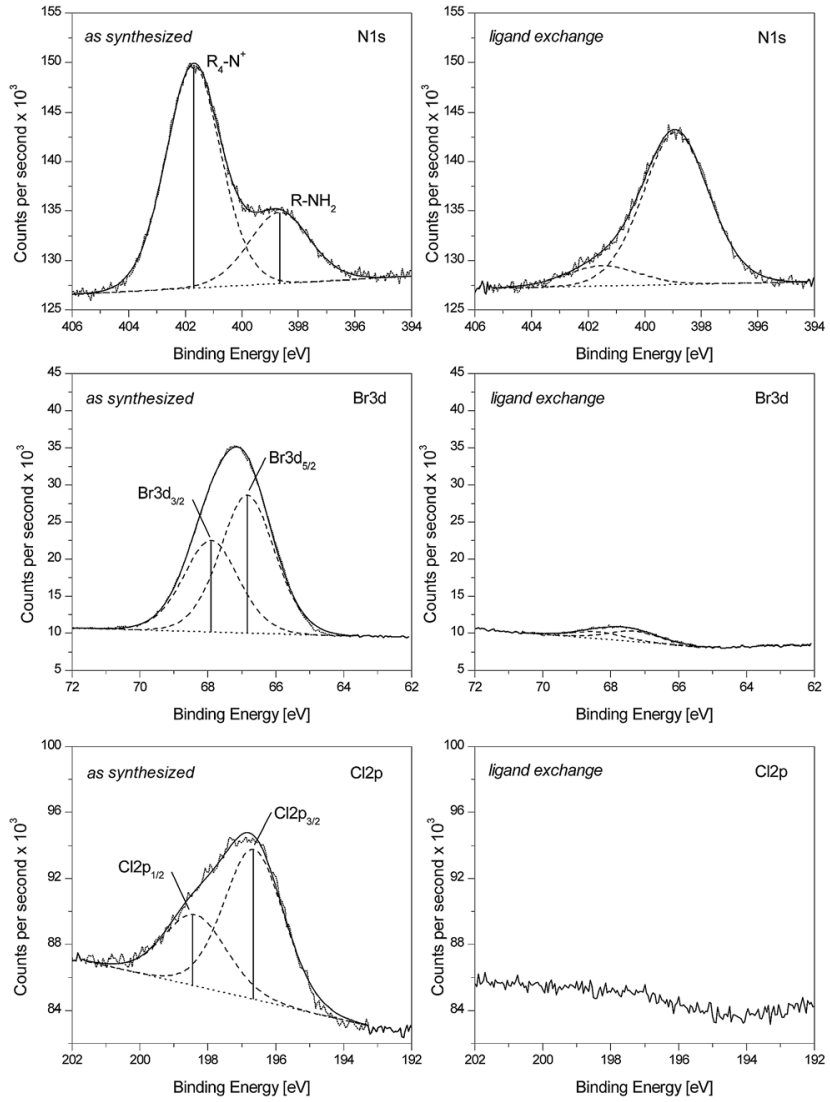

Fig. 3 Detailed XPS spectra from Au DDA nanoparticles for the N1s, $\mathrm{Br} 3 \mathrm{~d}$, and $\mathrm{Cl} 2 \mathrm{p}$ region. The left column represents the as-synthesized material after purification; the right column corresponds to the nanocrystals after heat treatment, purification, ligand exchange, and second purification. All spectra were recorded with $100 \mathrm{eV}$ pass energy, $0.05 \mathrm{eV}$ step size, and $100 \mathrm{~ms}$ dwell time averaged for 10 scans.

the $\operatorname{Br} 3 \mathrm{~d}_{3 / 2}$ at $67.9 \mathrm{eV}$, respectively. This indicates that there is only one species of bromine at the nanoparticle surface. From comparison to literature data the signal can be assigned to bromide. ${ }^{105}$

Similar conclusions can be drawn for the $\mathrm{Cl} 2 \mathrm{p}$ region. There are also two signals referring to the $\mathrm{Cl} 2 \mathrm{p}_{3 / 2}$ at $196.5 \mathrm{eV}$ and the $\mathrm{Cl} 2 \mathrm{p}_{1 / 2}$ at $198.2 \mathrm{eV}$. Again, from comparison to literature data the signal can be assigned to chloride. ${ }^{\mathbf{1 0 6}}$ All correlations for bromine, chlorine, and nitrogen to particular chemical species were also verified by reference measurements with the used chemicals as described above.

In conclusion, these results show that the investigated $\mathrm{Au}$ nanoparticles are not only stabilized by amine ligands but there are also bromide, chloride and quaternary ammonia coadsorbates present. With respect to the high requirements for defined and unsoiled materials for technological processes and model catalysis, this is an important problem.

Though there are usually a lot of potential adsorbates used in the synthesis of nanomaterials, the coadsorption of other molecules than the intended ligand is often ignored in the literature. Especially mixtures of non-polar and polar or even ionic species are not considered.
The ammonia and especially the halides signals originate from the nanoparticle surface and are not contamination of the XPS sample coming from the purification steps. This is indicated by scanning TEM and energy dispersive X-ray spectroscopy investigations, which show that there is no bromine and less nitrogen in the background of the TEM grid in contrast to the nanoparticles.

The next step is to have a closer look at the changes effected by heat treatment, ligand exchange, and second purification. This procedure reduces the intensity of the signal at $401.4 \mathrm{eV}$ while it increases the one at $398.9 \mathrm{eV}$. Furthermore, the signals at 66.9 and $67.9 \mathrm{eV}$ and $196.5 \mathrm{eV}$ and $198.2 \mathrm{eV}$ corresponding to the halides are dramatically decreased. Overall this indicates bromide, chloride, and ammonia being replaced by the amine during this procedure. The actual replacement is not sensitive to the ligand molecules but to the ratio of the respective surfactant concentration, as later results will show.

\section{New insights into stabilization mechanism - quantification of XPS results}

As XPS is a quantifiable technique, it is straightforward to have a closer look at the amounts of the adsorbed molecules. For this purpose, the signals belonging to ammonia, amine, chloride and bromide were quantified. It is assumed that these four species are the only surfactants of importance. As each molecule or ion contains only one atom of nitrogen, bromine or chlorine the sensitivity weighted integrals can simply be added and normalized to be $100 \%$ in sum. To prevent random fluctuations more than four samples for each step and ligand were measured and the data received were averaged.

The results of this quantitative data analysis are shown in Fig. 4. In the case of the as-synthesized nanoparticles, it is evident that the surface composition is highly depending on the ligand.

The Au OA nanoparticles exhibit a high ratio of amine $(\approx 65 \%)$ in comparison to the other surfactants. This may be attributed to the long hydrocarbon chain with a strong stabilizing effect so that there is less space for ionic components to adsorb. The possible $\pi$-electron interactions via the double bond unit in the hydrocarbon chain apparently consolidate the strong interactions between the OA molecules.

With smaller chain length more ionic substances can adsorb on the nanoparticle surface. In the case of Au DDA nanoparticles about the fourfold amount of ionic compounds compared to the amine $(\approx 20 \%)$ is present. As the density of adsorbed molecules is lower in the case of tertiary amines due to their high sterical demand in the lateral direction, many ions may adsorb on the nanoparticles resulting in an even lower amine fraction $(\approx 15 \%)$ than Au DDA.

Detailed spectra for the N1s region for Au DDAB nanocrystals showed not only the prominent ammonia signal at $401.4 \mathrm{eV}$ but also a slight shoulder at $398.9 \mathrm{eV}$, which would be corresponding to amine molecules. There is no amine in the case of the $\mathrm{Au}$ DDAB nanoparticles. Minor contamination with amine compounds could originate from samples that were measured before or after and remained inside the UHV chamber. Au DDAB 


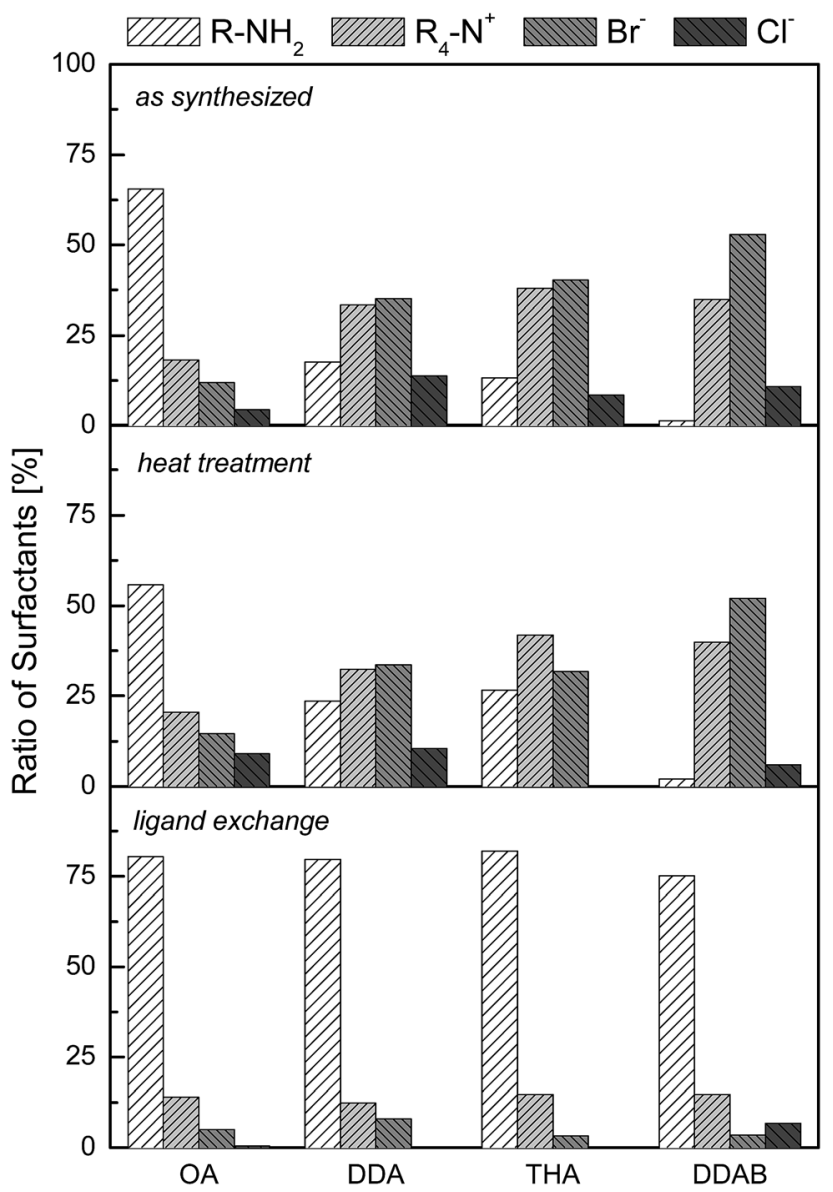

Fig. 4 Averaged results of quantitative XPS analysis for Au OA, Au DDA, Au THA and Au DDAB nanoparticles as synthesized, during the ripening and ligand exchange steps. Signals were normalized to $100 \%$ for the total integral of all four components.

nanoparticles also exchanged anions hence there is not only bromide but also chloride measurable within these samples.

\section{Discussion}

After heat treatment, purification, ligand exchange and second purification Au OA, Au DDA and Au THA nanocrystals feature a similar surfactant composition containing around $80 \%$ amine and about $20 \%$ ionic compounds. Chloride is removed completely. As those nanostructures have the same surfactant composition after ligand exchange, we can discuss the observations from TEM and quantitative XPS studies about ligand properties like hydrocarbon chain length and sterical demand.

Oleylamine molecules offer high sterical stabilization via their long hydrocarbon chains and strong ligand-ligand interactions. Ionic compounds are apparently unimportant coadsorbates on Au OA nanoparticles in terms of stabilization. Heat treatment has no impact due to the high stability of the ligand shell. In this particular case, not only the long hydrocarbon chain but also interactions by $\pi$-electrons from the double bond units may enforce the interaction. Transformation processes are not possible because of the strong shielding. The stabilization of the as-synthesized material is well developed as ligand exchange only reduces the little ionic contaminations. This is in good correlation with several publications which point out the role of oleylamine as a strong stabilizing agent in nanoparticle formation. ${ }^{107,108}$

As sterical forces are weaker in the case of DDA in comparison to OA, ionic compounds gain in importance for Au DDA nanocrystals. The weaker stabilization manifests in the larger particle size. Ionic compounds are coadsorbates that complete the shielding of the nanoparticles for the as-synthesized material. Heat treatment induces Ostwald ripening leading to slight particle growth as the statistical size analysis illustrates (see ESI Fig. S1 $\dagger$ ). This is possible since the bonding of the ionic compounds is apparently weaker than the bonding of the amine molecules ascribed to the free electron pair at the amine group. Similar results on the stabilizing forces of amine molecules adsorbed onto nanoparticles were reported by Peng et al. ${ }^{109}$ DDA molecules are also able to stabilize Au nanoparticles, since the $\mathrm{Au}$ DDA particles are stable even after ligand exchange.

THA consists of even smaller hydrocarbon chains and leads to a low ligand density as apparent from quantitative XPS because of its high sterical demand. However, in the case of $\mathrm{Au}$ THA nanoparticles, the sterical forces via the hydrocarbon chains are of minor importance as the stabilization is provided via the ionic compounds. Heat treatment induces some digestive ripening leading to smaller particles. This differs from $\mathrm{Au}$ DDA nanoparticles and suggests that the ionic compounds are dominant during heat treatment. A removal of ionic compounds and an increase in amine concentration during ligand exchange leads to the agglomeration of the nanoparticles to nanoporous structures as shown exemplary in Fig. 1i. Therefore, single trihexylamine molecules are not able to prevent agglomeration via sterical forces on their own because their hydrocarbon chains are too small and the density of adsorbed molecules is not high enough to provide colloidal stability. In comparison functionalized and branched polymers with tertiary amine groups such as polyamidoamines or polyalkyleneimines are able to prevent agglomeration due to the simultaneous adsorption because of chelate effects. ${ }^{110,111}$

In the case of the Au DDAB nanoparticles, apparently there are only ionic compounds adsorbed on the as-synthesized particles to provide the stabilization. One should keep in mind that ionic ammonia ions exhibit both sterical forces as well as electrostatic ones. Similar nanomaterials stabilized by quaternary ammonia compounds are well known in the literature. ${ }^{91,100}$ As observed before, ionic adsorbates allow ripening during heat treatment. In this case, Ostwald ripening is observed as smaller particles are consumed for growth of the bigger ones (Fig. 1k). After ligand exchange with OA, small nanoparticles with a surfactant composition similar to assynthesized Au OA nanoparticles are obtained.

In conclusion, depending on the properties of the ligand molecules the actual stabilization seems to be a combination of sterical and electrostatic effects. Instead of sterical shielding electrostatic forces get more important when the stabilization by the ligand gets weaker. For example, ionic compounds and amine ligand molecules are both significantly engaged in 
preventing agglomeration of Au DDA nanoparticles. In contrast, the sterical forces of the hydrocarbon chains are of minor importance in the case of Au THA nanoparticles as the stabilization is provided by the ionic compounds. This is unusual because ionic compounds are likely considered to be absent if nanomaterials are soluble in organic solution. ${ }^{7,86,87,112}$ Due to the dynamic adsorption of surfactants, it is possible to adjust the surfactant composition in the required way via simple exchange procedures. The different ligand exchange steps presented in this work indicate a universal system for amines and ionic compounds as well as other surfactant molecules like thiols, carbonic acids or phosphine derivatives. The comparable adsorption with different bonding strength to the surface has already be shown in literature for different ligands. ${ }^{71,75,113,114}$

As the presence of cationic and anionic compounds is roughly correlated to another one could assume that there is some electric double layer present on the nanostructured surfaces. Kontturi et al. investigated the behavior of gold nanoparticles with defined electric double layers under varying conditions and pointed out the importance for solubility and exchange procedures. ${ }^{\mathbf{9 8}}$ The specific properties of such electric double layer arrangements are important for example for the adsorption of polar and apolar compounds because the accessibility to the gold surface is dependent on the electrostatic interactions with this double layer. In principle, this indicates the universal possibility to tune the accessibility of nanoparticle surfaces with respect to charged or polar compounds via adjustment of the surface composition.

One would expect that more polar precipitation agents will remove more ionic substances, but this is not the case. Different precipitation agents lead to similar results. Only small differences appear between the surfactant composition of $\mathrm{Au}$ nanocrystals that are precipitated with methanol or acetone. The ionic compounds seem to be adsorbed on the particles surface. Therefore, this is not a simple solubility problem as frequently discussed in the literature. ${ }^{115}$ This is demonstrated by our STEM and EDX studies.

The different stabilization modes are helpful for understanding the heat treatment. Surprisingly, there are no significant changes in the surfactant composition during this procedure. In the case of Au OA nanoparticles, no transformation is visible in TEM. This means that sterical stabilization by big molecules is not influenced by heat treatment. In all other cases with at least partial electrostatic stabilization ripening takes place. This is a clear hint that the adsorption of ionic compounds is sensitive to temperature. Any kind of reorganization is probably related to the ionic compounds. This leads to temporary possibilities for growth or ripening. One should also note that the heat treatment is mandatory to get rid of the chloride.

As the importance of ionic stabilizations gains in importance from $\mathrm{Au}$ DDA over $\mathrm{Au}$ THA to Au DDAB nanoparticles, the impact of heat treatment also gets stronger. Two types of ripening occur; namely, Ostwald ripening resulting in bigger particles as well as digestive ripening leading to a decrease in size. It is not clear why these two modes are present but it is possible that the ratio of electrostatic stabilization and the lateral sterical demand of the adsorbed molecules are responsible. This fits well with results by Klabunde et al. ${ }^{\mathbf{8 8 , 8 9 , 9 6}}$ who illustrated the ligand as a major parameter for ripening processes at elevated temperatures as well as findings by Shon et al. ${ }^{116}$ who pointed out the important role of different counterions for thermal stability of tetraoctylammonium protected gold nanoparticles in aqueous solution.

There are no changes in the microstructure of the nanoparticles in HR-TEM studies during the process of ripening and ligand exchange. Therefore, one can assume that the surfactant composition has no influence on the crystal structure in this case. This is important to know as the control of crystal surfaces is mandatory for catalysis and technological processes. The used model system does not show effects like adsorption induced reconstruction that can frequently be found in the literature. ${ }^{\mathbf{1 1 7}}$

\section{Conclusions}

In this work, quantitative XPS and HR-TEM results reveal that the stabilization of small gold nanoparticles with various amine ligands is achieved by an easily tuneable combination of sterical and electrostatic shielding depending on the ligand molecule properties. Not only the ligand molecules but also ionic compounds are involved in stabilization. These nanomaterials are sensitive to temperature changes as ionic compounds play an important role in processes like Ostwald or digestive ripening during mild heat treatment. Therefore, ammonia surfactants apparently provide a lower binding strength than amine molecules. These adsorbates have no influence on morphology and crystal structure.

The ratio of sterical and electrostatic stabilization is accessible via simple replacement procedures under mild conditions. Thus it is possible to adjust the surfactant composition to technological requirements. This method is suitable to get small nanoparticles as long as the ligand can provide enough sterical forces to prevent agglomeration. Aggregation of such gold nanostructures without sufficient stabilization leads to porous networks.

\section{Acknowledgements}

Our sincere thanks go to Prof. Dr K. Al-Shamery for the allocation of laboratory and equipment as well as for very helpful discussions. Helpful discussions with Prof. Dr J. Kolny-Olesiak are gratefully acknowledged. Both decided not to be coauthor as they felt that they did not substantially contribute enough to this manuscript to earn the right for coauthorship. Thanks to Dr E. Rhiel, U. Friedrich and E. Kieselhorst for assistance with the electron microscopy measurements. The funding of the JEOL JEM2100F HR-TEM by the Deutsche Forschungsgemeinschaft (INST 184/106-1 FUGG) is acknowledged. The Thermo Fisher ESCALAB 250 Xi XPS device was supported by the Deutsche Forschungsgemeinschaft (INST 184/144-1FUGG).

\section{Notes and references}

1 A.-K. Herrmann, P. Formanek, L. Borchardt, M. Klose, L. Giebeler, J. Eckert, S. Kaskel, N. Gaponik and A. Eychmüller, Chem. Mater., 2014, 26, 1074-1083. 
2 C. Raab, M. Simkó, U. Fiedeler, M. Nentwich and A. Gazsó, Nano Trust Dossiers, 2008, 1-4.

3 N. Li, P. Zhao and D. Astruc, Angew. Chem., 2014, 126, 17841818.

4 M.-C. Daniel and D. Astruc, Chem. Rev., 2004, 104, 293-346.

5 K.-A. Höpker, U. Wurster, G. Kunigkeit and G. Ott, Anwendung von Nanopartikeln, Karlsruhe, 2007.

6 I. Papp, C. Sieben, K. Ludwig, M. Roskamp, C. Böttcher, S. Schlecht, A. Herrmann and R. Haag, Small, 2010, 6, 2900-2906.

7 J. You, R. Zhang, G. Zhang, M. Zhong, Y. Liu, C. S. Van Pelt, D. Liang, W. Wei, A. K. Sood and C. Li, J. Controlled Release, 2012, 158, 319-328.

8 X. Yang, S. E. Skrabalak, Z. Li, Y. Xia and L. V Wang, Nano Lett., 2007, 7, 3798-3802.

9 R. Bardhan, S. Lal, A. Joshi and N. J. Halas, Acc. Chem. Res., 2011, 44, 936-946.

10 S. M. Yoo, T. Kang, H. Kang, H. Lee, M. Kang, S. Y. Lee and B. Kim, Small, 2011, 7, 3371-3376.

11 S. K. Dondapati, T. K. Sau, C. Hrelescu, T. A. Klar, F. D. Stefani and J. Feldmann, ACS Nano, 2010, 4, 63186322.

12 K. Topp, H. Borchert, F. Johnen, A. V. Tunc, M. Knipper, E. von Hauff, J. Parisi and K. Al-Shamery, J. Phys. Chem. A, 2010, 114, 3981-3989.

13 L. Polavarapu, K. K. Manga, K. Yu, P. K. Ang, H. D. Cao, J. Balapanuru, K. P. Loh and Q.-H. Xu, Nanoscale, 2011, 3, 2268-2274.

14 M. Osmić, J. Kolny-Olesiak and K. Al-Shamery, CrystEngComm, 2014, 16, 9907-9914.

15 A. Schroedter and H. Weller, Angew. Chem., 2002, 114, 33463350.

16 F. Schüth, Chemie in unserer Zeit, 2006, 40, 92-103.

17 A. T. Bell, Science, 2003, 299, 1688-1691.

18 S. K. Hashmi and G. J. Hutchings, Angew. Chem., Int. Ed., 2006, 45, 7896-7936.

19 Y. Kuwauchi, H. Yoshida, T. Akita, M. Haruta and S. Takeda, Angew. Chem., 2012, 124, 7849-7853.

20 M. Haruta, Nature, 2005, 437, 1098-1099.

21 M. Haruta, T. Kobayashi, H. Sano and N. Yamada, Chem. Lett., 1987, 16, 405-408.

22 M. Haruta, J. Catal., 1989, 115, 301-309.

23 J. Schwank, Gold Bull., 1983, 16, 103-110.

24 C. W. Corti and R. J. Holliday, Gold Bull., 2004, 37, 20-26.

25 G. C. Bond, P. A. Sermon, G. Webb, D. A. Buchanan and P. B. Wells, J. Chem. Soc., Chem. Commun., 1973, 444b.

26 T. Ishida and M. Haruta, Angew. Chem., 2007, 119, 72887290.

27 T. Hayashi, K. Tanaka and M. Haruta, J. Catal., 1998, 178, 566-575.

28 L. Prati and M. Rossi, J. Catal., 1998, 176, 552-560.

29 A. Ueda and M. Haruta, Gold Bull., 1999, 32, 3-11.

30 G. Pattrick, E. van der Lingen, C. W. Corti, R. J. Holliday and D. T. Thompson, Top. Catal., 2004, 30/31, 273-279.

31 M. McEntee, W. Tang, M. Neurock and J. T. Yates, J. Am. Chem. Soc., 2014, 136, 5116-5120.
32 T. Akita, M. Kohyama and M. Haruta, Acc. Chem. Res., 2013, 46, 1773-1782.

33 D. Widmann and R. J. Behm, Angew. Chem., 2011, 123, 10424-10428.

34 X. Liu, M. Liu, Y. Luo, C. Mou, S. D. Lin, H. Cheng, J. Chen, J. Lee and T. Lin, J. Am. Chem. Soc., 2012, 134, 10251-10258.

35 Y. Yuan, K. Asakura, H. Wan, K. Tsai and Y. Iwasawa, Catal. Lett., 1996, 42, 15-20.

36 S. Carrettin, P. Concepción, A. Corma, J. M. López Nieto and V. F. Puntes, Angew. Chem., Int. Ed., 2004, 43, 2538-2540.

37 M. Haruta, CATTECH, 2002, 6, 102-115.

$38 \mathrm{Q}$. Fu, H. Saltsburg and M. Flytzani-Stephanopoulos, Science, 2003, 301, 935-938.

39 P. P. Edwards and J. M. Thomas, Angew. Chem., 2007, 119, 5576-5582.

40 B. R. Cuenya, Thin Solid Films, 2010, 518, 3127-3150.

41 M. B. Boucher, S. Goergen, N. Yi and M. FlytzaniStephanopoulos, Phys. Chem. Chem. Phys., 2011, 13, 25172527.

42 M. Comotti, W.-C. Li, B. Spliethoff and F. Schüth, J. Am. Chem. Soc., 2006, 128, 917-924.

43 C. Harding, V. Habibpour, S. Kunz, A. N. Farnbacher, U. Heiz, B. Yoon and U. Landman, J. Am. Chem. Soc., 2009, 131, 538-548.

44 W.-L. Yim, T. Nowitzki, M. Necke, H. Schnars, P. Nickut, J. Biener, M. M. Biener, V. Zielasek, K. Al-Shamery, T. Klüner and M. Bäumer, J. Phys. Chem. C, 2007, 111, 445-451.

45 R. Meyer, C. Lemire, S. K. Shaikhutdinov and H.-J. Freund, Gold Bull., 2004, 37, 72-124.

46 J. Gong, Chem. Rev., 2012, 112, 2987-3054.

47 W. D. Williams, M. Shekhar, W. Lee, V. Kispersky, W. N. Delgass, F. H. Ribeiro, S. M. Kim, E. A. Stach, J. T. Miller and L. F. Allard, J. Am. Chem. Soc., 2010, 132, 14018-14020.

48 S. K. Shaikhutdinov, R. Meyer, M. Naschitzki, M. Bäumer and H.-J. Freund, Catal. Lett., 2003, 86, 211-219.

49 Y. Xia, Y. Xiong, B. Lim and S. E. Skrabalak, Angew. Chem., 2009, 121, 62-108.

50 J. Park, J. Joo, S. G. Kwon, Y. Jang and T. Hyeon, Angew. Chem., 2007, 119, 4714-4745.

51 Y. Wang, J. He, C. Liu, W. H. Chong and H. Chen, Angew. Chem., Int. Ed., 2015, 54, 2022-2051.

52 R. Sardar, A. M. Funston, P. Mulvaney and R. W. Murray, Langmuir, 2009, 25, 13840-13851.

53 S. Tsubota, T. Nakamura, K. Tanaka and M. Haruta, Catal. Lett., 1998, 56, 131-135.

54 D. Fenske, P. Sonström, J. Stöver, X. Wang, H. Borchert, J. Parisi, J. Kolny-Olesiak, M. Bäumer and K. Al-Shamery, ChemCatChem, 2010, 2, 198-205.

55 H. Borchert, D. Fenske, J. Kolny-Olesiak, J. Parisi, K. AlShamery and M. Bäumer, Angew. Chem., Int. Ed., 2007, 46, 2923-2926.

56 C. Jia, Y. Liu, H. Bongard and F. Schüth, J. Am. Chem. Soc., 2010, 132, 1520-1522. 
57 J. C. Matsubu, S. Zhang, L. DeRita, N. S. Marinkovic, J. G. Chen, G. W. Graham, X. Pan and P. Christopher, Nat. Chem., 2016, 9, 120-127.

58 Z. Jiang, W. Zhang, L. Jin, X. Yang, F. Xu, J. Zhu and W. Huang, J. Phys. Chem. C, 2007, 111, 12434-12439.

59 B. Chowdhury, J. J. Bravo-Suárez, M. Daté, S. Tsubota and M. Haruta, Angew. Chem., Int. Ed., 2006, 45, 412-415.

60 L. Altmann, S. Kunz and M. Bäumer, J. Phys. Chem. C, 2014, 118, 8925-8932.

61 M. Faraday, Philos. Trans. R. Soc. London, 1857, 147, 145181.

62 J. Turkevich, P. C. Stevenson and J. Hillier, Discuss. Faraday Soc., 1951, 11, 55-78.

63 W. Ostwald, Zeitschrift für Chemie und Industrie der Kolloide, 1909, 4, 5-14.

64 M. Brust, M. Walker, D. Bethell, D. J. Schiffrin and R. Whyman, J. Chem. Soc., Chem. Commun., 1994, 801-802.

65 M. B. Mohamed, K. M. AbouZeid, V. Abdelsayed, A. A. Aljarash and M. S. El-Shall, ACS Nano, 2010, 4, 27662772.

66 D. V. Leff, L. Brandt and J. R. Heath, Langmuir, 1996, 12, 4723-4730.

67 O. C. Compton and F. E. Osterloh, J. Am. Chem. Soc., 2007, 129, 7793-7798.

68 Y. Joseph, I. Besnard, M. Rosenberger, B. Guse, H.-G. Nothofer, J. M. Wessels, U. Wild, A. Knop-Gericke, D. Su, R. Schlögl, A. Yasuda and T. Vossmeyer, J. Phys. Chem. B, 2003, 107, 7406-7413.

69 A. Badia, S. Singh, L. Demers, L. Cuccia, G. R. Brown and R. B. Lennox, Chem.-Eur. J., 1996, 2, 359-363.

70 A. Kumar, S. Mandal, R. Pasricha, A. B. Mandale and M. Sastry, Langmuir, 2003, 19, 6277-6282.

71 H. Hiramatsu and F. E. Osterloh, Chem. Mater., 2004, 16, 2509-2511.

72 M. Yamamoto, Y. Kashiwagi and M. Nakamoto, Zeitschrift für Naturfoschung B, 2009, 64, 1305-1311.

73 W. W. Weare, S. M. Reed, M. G. Warner and J. E. Hutchison, J. Am. Chem. Soc., 2000, 122, 12890-12891.

74 M. Green and P. O'Brien, Chem. Commun., 2000, 183-184.

75 J. Song, D. Kim and D. Lee, Langmuir, 2011, 27, 1385413860.

76 H. Tsunoyama, P. Nickut, Y. Negishi, K. Al-Shamery, Y. Matsumoto and T. Tsukuda, J. Phys. Chem. C, 2007, 111, 4153-4158.

77 I. Hussain, S. Graham, Z. Wang, B. Tan, D. C. Sherrington, S. P. Rannard, A. I. Cooper and M. Brust, J. Am. Chem. Soc., 2005, 127, 16398-16399.

78 Y. Sun and Y. Xia, Science, 2002, 298, 2176-2179.

79 J. Polte, T. T. Ahner, F. Delissen, S. Sokolov, F. Emmerling, A. F. Thünemann and R. Kraehnert, J. Am. Chem. Soc., 2010, 132, 1296-1301.

80 S. Kumar, K. S. Gandhi and R. Kumar, Ind. Eng. Chem. Res., 2007, 46, 3128-3136.

81 B. Nikoobakht and M. A. El-Sayed, Langmuir, 2001, 17, 6368-6374.

82 N. R. Jana, L. Gearheart and C. J. Murphy, Adv. Mater., 2001, 13, 1389-1393.
83 G.-T. Wei, Z. Yang, C.-Y. Lee, H.-Y. Yang and C. R. C. Wang, J. Am. Chem. Soc., 2004, 126, 5036-5037.

84 K. Kim, D. Demberelnyamba and H. Lee, Langmuir, 2004, 20, 556-560.

85 K. S. Kim, S. Choi, J. H. Cha, S. H. Yeon and H. Lee, J. Mater. Chem., 2006, 16, 1315-1317.

86 M. M. Maye, W. Zheng, F. L. Leibowitz, N. K. Ly and C. J. Zhong, Langmuir, 2000, 16, 490-497.

87 S. R. K. Perala and S. Kumar, Langmuir, 2013, 29, 98639873.

88 B. L. V. Prasad, S. I. Stoeva, C. M. Sorensen and K. J. Klabunde, Chem. Mater., 2003, 15, 935-942.

89 S. I. Stoeva, V. Zaikovski, B. L. V. Prasad, P. K. Stoimenov, C. M. Sorensen and K. J. Klabunde, Langmuir, 2005, 21, 10280-10283.

90 M. Ganguly, A. Pal and T. Pal, J. Phys. Chem. C, 2012, 116, 9265-9273.

91 M. J. Hollamby, J. Eastoe, A. Chemelli, O. Glatter, S. Rogers, R. K. Heenan and I. Grillo, Langmuir, 2010, 26, 6989-6994. 92 L. O. Brown and J. E. Hutchison, J. Am. Chem. Soc., 1999, 121, 882-883.

93 Z. Cao, D. Kim, D. Hong, Y. Yu, J. Xu, S. Lin, X. Wen, E. M. Nichols, K. Jeong, J. A. Reimer, P. Yang and C. J. Chang, J. Am. Chem. Soc., 2016, 138, 8120-8125.

94 N. R. Jana and X. Peng, J. Am. Chem. Soc., 2003, 125, 1428014281.

95 C. Arribas, D. R. Rueda and J. L. G. Fierro, Langmuir, 1991, 7, 2682-2686.

96 B. L. V. Prasad, S. I. Stoeva, C. M. Sorensen and K. J. Klabunde, Langmuir, 2002, 18, 7515-7520.

97 K. Wettergren, F. F. Schweinberger, D. Deiana, C. J. Ridge, A. S. Crampton, M. D. Rötzer, T. W. Hansen, V. P. Zhdanov, U. Heiz and C. Langhammer, Nano Lett., 2014, 14, 5803-5809.

98 T. Laaksonen, P. Ahonen, C. Johans and K. Kontturi, ChemPhysChem, 2006, 7, 2143-2149.

99 A. Dass, R. Guo, J. B. Tracy, R. Balasubramanian, A. D. Douglas and R. W. Murray, Langmuir, 2008, 24, 310315.

100 C. J. Johnson, E. Dujardin, S. A. Davis, C. J. Murphy and S. Mann, J. Mater. Chem., 2002, 12, 1765-1770.

101 M. P. Seah, I. S. Gilmore and G. Beamson, Surf. Interface Anal., 1998, 26, 642-649.

102 J. Radnik, C. Mohr and P. Claus, Phys. Chem. Chem. Phys., 2003, 5, 172-177.

103 Z. Huo, C. Tsung, W. Huang, X. Zhang and P. Yang, Nano Lett., 2008, 8, 2041-2044.

104 S. D. Techane, L. J. Gamble and D. G. Castner, Biointerphases, 2011, 6, 98-104.

105 S. Hoste, D. F. Van De Vondel and G. P. Van Der Kelen, J. Electron Spectrosc. Relat. Phenom., 1979, 17, 191-195.

106 C. Sleigh, A. P. Pijpers, A. Jaspers, B. Coussens and R. J. Meier, J. Electron Spectrosc. Relat. Phenom., 1996, 77, 41-57.

107 S. Mourdikoudis and L. M. Liz-Marzán, Chem. Mater., 2013, 25, 1465-1476. 
108 Z. Xu, C. Shen, Y. Hou, H. Gao and S. Sun, Chem. Mater., 2009, 21, 1778-1780.

109 N. Pradhan, D. Reifsnyder, R. Xie, J. Aldana and X. Peng, J. Am. Chem. Soc., 2007, 129, 9500-9509.

110 R. M. Crooks, M. Zhao, L. Sun, V. Chechik and L. K. Yeung, Acc. Chem. Res., 2001, 34, 181-190.

111 M. Zhao and R. M. Crooks, Chem. Mater., 1999, 11, 33793385.

112 B. L. V. Prasad, C. M. Sorensen and K. J. Klabunde, Chem. Soc. Rev., 2008, 37, 1871.
113 M. Hostetler, A. Templeton and R. Murray, Langmuir, 1999, 3782-3789.

114 K. G. Thomas and P. V. Kamat, Acc. Chem. Res., 2003, 36, 888-898.

115 W. Zhao, T. M. H. Lee, S. S. Y. Leung and I.-M. Hsing, Langmuir, 2007, 23, 7143-7147.

116 S. R. Isaacs, E. C. Cutler, J.-S. Park, T. R. Lee and Y.-S. Shon, Langmuir, 2005, 21, 5689-5692.

117 L. M. Molina and B. Hammer, Chem. Phys. Lett., 2002, 360, 264-271. 